https://doi.org/10.47370/2078-1024-2021-13-3-147-156

УДК 37.017.4:34

Чумичева Р.М., Габович А.А.

НАУЧНО-ТЕОРЕТИЧЕСКИЕ ОСНОВЫ

ПРОЕКТИРОВАНИЯ МОДЕЛИ ФОРМИРОВАНИЯ

ГРАЖДАНСКОЙ ПОЗИЦИИ БУДУЩИХ ЮРИСТОВ

\author{
Чумичева Раиса Михайловна, \\ доктор педагогических наук, профессор кафедры дошкольного образования \\ ФГАОУ ВО «Южный федеральный'унивөрситет», Ростов-на-Дону, Россия, \\ e-mail: rmchumicheva@sfedu.ru, \\ tel.: +7 (928) 2293017
}

Габович Антон Александрович, ассистент кафедры конституционного и муниципального права Ростовский государствениый экономический университет (РИНХ), Ростов-наДону, Россия,

e-mail: gabiant124@gmail.com

тел.: +7 (919) 8942209

\begin{abstract}
Аннотация
Актуальность исследования определяется необходимостью поиска новых научно-теоретических, методических, содержательных и технологических основ подготовки будущих юристов как интеллектуальной и политической элиты государства, владеющей устойчивой гражданской позицией и готовой к формированию гражданского общества и защиты прав граждан России. Проблема исследования состоит в изучении особенностей подготовки будущих юристов и определение научно-теоретической платформы проектирования модели формирования гражданской позиции будущих юристов в юридической клинике университета. Цель исследования: научное обоснование и проектирование модели формирования гражданской позиции будущих юристов в юридической клинике университета. Методология и методы исследования: контент-анализ научных исследований; теоретический анализ педагогических дилемм в подготовке будущих юристов; прогнозы педагогических фронтиров для разработки условий развития гражданской позиции будущих юристов в процессе профессиональной подготовки; проектирование модели развития гражданской позиции будущих юристов в юридической клинике университета. Результаты исследования: трансформационные процессы в мире изменяют гражданское общество (социальное расслоение, незащищенность прав отдельной части социума и др.), становятся вызовами современному образованию в подготовке будущих юристов; интеграция и междисциплинарный подход в подготовке будущих юристов определяют научно-теоретические, методические, содержательные и технологические подходы к развитию гражданской позиции будущего юриста; проектирование модели развития гражданской позиции будущих юристов в юридической клинике университета позволяет осуществить прогнозы на востребованные компетенции данной категории специалистов, оптимизировать средовые
\end{abstract}


условия университета - юридическая клиника как место профессиональной самореализации и проявление гражданской позиции будущего юриста. Ключевые выводы: глобальные тенденции являются вызовами для современного юридического образования; подготовка будущих юристов должна быть спряжена с формированием гражданской позиции, понимаемой как готовность служить своему Отечеству, государству и ее гражданам; проектирование инновационных моделей подготовки будущих юристов ориентировано на интеграцию процессов профессионального становления и воспитания будущего гражданина России с устойчивой гражданской позицией, на опережающий характер освоения будущими юристами в юридической клинике университета профессиональных и личностных компетенций, востребованных в правовом государстве.

Ключевые слова: юридическое образование, модель формирования гражданской позиции будущих юристов, юридическая клиника

Для читирования: Чумичева Р.Ми, Габович А.А. Научио-теоретические осповы проектирования 'модели формирования аражданской позичии будуиих юристов /" Вестник Майкопского государственного технологического университета. 2021. Том 13, № 3. C. 147-156. https:/doi.org/10.47370/2078-1024-2021-13-3-147-156.

Chumicheva R.M., Gabovich A.A.

\title{
SCIENTIFIC AND THEORETICAL BASES FOR DESIGNING A MODEL FOR FORMING FUTURE LAWYERS' CIVIC-MINDEDNESS
}

\author{
Chumicheva Raisa Mikhailovna, \\ Doctor of Pedagogy, a professor of the Department of Preschool Education \\ of FSAEI HE "The Southern Federal University", Rostov-on-Don, Russia, \\ e-mail: rmchumicheva@sfedu.ru, \\ tel.: +7 (928) 2293017 \\ Gabovich Anton Alexandrovich, \\ an assistant lecturer of the Department of Constitutional and Municipal Law, \\ Rostov State Economic University (RINH), Rostov-on-Don, Russia, \\ e-mail: gabiant124@gmail.com \\ tel.: +7 (919) 8942209
}

\section{Annotation}

The relevance of the research is determined by the need to search for new scientific, theoretical, methodological, substantive and technological foundations for the training future lawyers, as the intellectual and political elite of the state, possessing a stable civic position and ready to form a civil society and protect the rights of Russian citizens. The problem of the research is to study the features of training future lawyers and to determine the scientific and theoretical platform for designing a model for the formation of civic position of future lawyers in the legal clinic of a university. The purpose of the research is scientific substantiation and design of a model for the formation of the civic position of future lawyers in the legal clinic of a university. The research methodology and methods: content analysis of scientific research; theoretical analysis of pedagogical dilemmas in the training of future lawyers; forecasts of pedagogical fronts for the development of conditions for the development of the civic position of future lawyers in the process of professional training; designing a model for the development of the civic position of future lawyers in the legal clinic of a university. 
The research results are: transformational processes in the world change civil society (social stratification, lack of protection of the rights of a separate part of society, etc.) and become challenges to modern education in the training of future lawyers; integration and an interdisciplinary approach in the training of future lawyers determine scientific-theoretical, methodological, substantive and technological approaches to the development of the civil position of a future lawyer; designing a model for the development of the civic position of future lawyers in the legal clinic of a university makes it possible to make forecasts for the required competencies of this category of specialists, optimize the environment of a university - a legal clinic as a place of professional self-realization and manifestation of the civic position of a future lawyer. Key findings are: global trends are challenges for modern legal education; the training of future lawyers should be coupled with the formation of a civic position, understood as a willingness to serve their Fatherland, the state and its citizens; the design of innovative models for the training of future lawyers is focused on the integration of the processes of professional formation and education of a future citizen of Russia with a stable civic position, on the anticipatory nature of the development by future lawyers in the legal clinic of university of professional and personal competencies in demand in the rule of law.

Keywords: legal education, model of formation of civil position of future lawyers, legal clinic

For citation: Chumicheva R.M, Gabovich A.A. Scientific and theoretical bases for designing a model for forming future lawyers' civic-mindedness /V Vestnik Majkopskogo 'gosudarstvennogo tehnologiceskogo universiteta. 2021. Volume 13, No. 3. P. 147-156. https:/doi. org/10.47370/2078-1024-2021-13-3-147-156.

Интеграция российского образования в глобальное образовательное пространство обусловила необходимость пересмотра научно-теоретических, методических, содержательных и технологических основ подготовки кадров в высшей школе, что коснулось и юридического образования. «Миссия университетов, отмечают Donetskaya O., Golovanova I., - заключается в подготовке интеллектуальной и политической элиты, т.е. людей и специалистов, готовых взять на себя ответственность за судьбу своей страны и человечества в целом» $[16$, с. 535]. Авторы подчеркивают, что качество гражданского воспитания зависит от технологий, которые используют преподаватели, в частности отмечены ценности поисковых моделей, которые самостоятельно создают студенты и преподаватели на основе партнерства, актуализируют развитие компонентов гражданской компетентности (предметной, методической) и личностной компетентности. В научных дискуссия высветились различные точки зрения ученых на поставленные проблемы подготовки будущих юристов [3; 6; 9 ;
$11 ; 13 ; 14$ и др.]. Суть дискуссии заключается в том, что юридическое образования в силу его специфики считается элитарным и корпоративным, замкнутым и кастовым, но при этом «...это регулятор поведения людей, общественных отношений между ними, а значит, оно должно быть адекватно этим отношениям, вытекать из их существа. Ключевой задачей юридического образования выступает поиск баланса между профессионализацией, кастовостью и специализацией - c одной стороны, и глубокой включенностью в национально-культурные процессы страны - с другой» $[3 ; 6]$. В контексте нашего исследования привлекает мысль авторов о том, что юридическое образование в России связано с национальной традицией служения государству и, как справедливо заметил В.А. Томсинов, направлено на подготовку «...не просто знатоков права, но государственно мыслящих, преданных своему Отечеству и потому способных к успешной государственной деятельности молодых людей» $[14$, с. 55]. На наш взгляд, будущие юристы, способные служить Отечеству, 
государству, должны обладать высоким чувством долга и иметь устойчивую гражданскую позицию, которая проявляется в культурной идентичности, в ответственности за принятые решения, способности изменять правовое сознание граждан, защищать их права и т.п. Гуманизация высшего образования изменила организационно-методические основы образовательного процесса в подготовке будущих юристов; обусловила модульный принцип проектирования образовательных программ, позволяющих эффективно освоить необходимые для будущей профессиональной деятельности компетенции, принцип ответственности за качество своей профессиональной подготовки, балльно-рейтинговую систему самооценки освоенных компетенций и проявленных личностных качеств, значимых для будущей профессиональной деятельности, принцип актуализации диалого-коммуникативных и цифровых технологий, направленных на развитие способности самостоятельно осваивать знания, навыки, умения, определять путь личностного и гражданского развития. Обозначенные принципы определили научные основы проектирования структурно-организационной модели формирования гражданской позиции будущих юристов в процессе профессиональной подготовки. Гуманизация юридического образования модернизировала его цели - формирование профессионально личностных качеств будущего юриста, способного защищать интересы каждого гражданина и общества в целом от нарушений законных прав и морали. Е.А. Семенов к профессиональным личностным качествам относит гражданственность, нравственность, чувство долга, ответственность и др., что требует оптимизации содержания профессиональной подготовки будущих юристов, активных методов обучения и психологических технологий формирования социальнопсихологических и профессиональных компетенций, психологического сопровождения студентов на всех этапах обучения [10]. Гражданская позиция личности выступает связующим звеном между социальной средой и внутренним миром человека, его мировоззрением, но при этом гражданская позиция личности способна менять внешний мир и свой мир. Данная проблема особо обострена в зарубежных исследованиях Raja Akermi, Abdelfattah Triki. Они отмечают значимость формирования гражданского общества и гражданских мотивов. Гражданское общество авторы понимают, как «...проявление гражданской позиции, выражение своих интересов, страстей и идей, обмена информацией, достижения общих целей, предъявления требований к государству» $[19$, c. 80$]$. Авторы отмечают, что понятие «гражданское общество» требует исследования и уточнения в контексте терминов «хорошее общество, ассоциативная жизнь, общественная сфера». Гражданское общество формируется на основе освоенных «ценностей», гражданских норм и демократических практик как областей человеческого взаимодействия. Гражданское общество понимается как форум, на котором обсуждаются социальные вопросы, организуется рациональный диалог, проявляется активная гражданская позиция в стремлении к общему благу. В работе авторов отмечена интересная для нашего исследования позиция, что гражданское общество формируется путем повышения осведомленности, подготовки кадров и распространения информации. Проблема взаимосвязи информации и развития общества раскрыта в исследованиях Jianan Guo, Muhammad AzizulIslam, Ameeta Jain, Chris J.van Staden, которые подчеркнули, что именно гражданские свободы, социальные движения обеспечивают прозрачность социальной и экологической информации и тем самым повышают гражданскую активность граждан, способствуют защите гражданских прав, инициируют 
изменения со стороны правительства и организаций в гражданском обществе, содействуют прозрачности корпоративной информации [17]. Для нашего исследования представили интерес работы, которые вскрывали проблемы специалистов правосудия и обращали внимание на подготовку будущих юристов, которые готовы к саморегуляции своего поведения при выполнении служебных обязанностей в обществе $[19 ; 20 ; 21]$. В связи с этим следует отметить, что формирование гражданской позиции будущих юристов определяется профессиональным самосознанием, становление которого происходит в процессе обучения в вузе при активном участии студентов в различных видах деятельности. Это дает основание предполагать, что привлечение студентов к активным видам профессиональной деятельности в социуме с гражданами позволяет осваивать не только профессиональные навыки и проявлять гражданскую позицию, ориентируясь на нормы морали, но и понять правовой статус гражданина. Ряд ученых подчеркивали значимость правового просвещения в воспитании уважения к праву и законности $[4 ; 10$ и др.]. Как отмечает С.В. Урванцева: «Юридические вузы не реализуют в полной мере воспитательный потенциал гражданско-компетентностной модели подготовки профессионала; вовлечение студентов в гражданские акции и мероприятия непоследовательно используется в качестве инструмента мотивации профессионального саморазвития, предусмотренного программами практики» [15, c. 129]. Обозначенная проблема требует своего решения, поскольку это актуализирует вопрос проектирования новых воспитательно-образовательных практико-ориентированных условий не только подготовки компетентного и конкурентоспособного юриста, но и гражданина с высоким уровнем ответственности и долга служения своему государству и его гражданам. Закономерная связь между гражданскими качествами юриста и его эффективной профессиональной деятельностью в «обеспечении безопасности нашего общества» отмечена в работе И.С. Ереминой [4, с. 173].

Компетентностный подход в профессиональной подготовке будущих юристов определил набор компетенций, сочетающих универсальные, общепрофессиональные и профессиональные компетенции как интеграцию профессиональных компетенций и личностных качеств выпускника вуза, где особое значение приобретает воспитание устойчивых гражданских качеств личности, среди которых мы определяем гражданскую позицию будущего юриста. Гражданская позиция человека является показателем социальной зрелости личности, готовой к профессиональной самореализации, саморазвитию, формированию правой культуры граждан. Компетентностный подход в формировании гражданской позиции будущих юристов в процессе профессиональной подготовки обусловил интеграцию и взаимодополнение содержания учебной и внеучебной деятельности, технологий теоретического и практического обучения и воспитания студентов в совместных видах деятельности во внеучебное время, усилил морально-нравственные основы практической профессиональной деятельности обучающихся. Компетентностный подход позволил определить критерии гражданской позиции будущих юристов как целевого ориентира в профессиональной подготовке бакалавров по направлению 40.03.01 Юриспруденция:

- когнитивный (наличие компетенций в вопросах конституционных и правовых норм, этики и норм морали);

- ценностно-смысловой (наличие ценностных ориентаций, гражданская активность, ответственность, справедливость, уважение и др.);

- нравственно-волевой (способность к диалогу, самоконтролю, саморегуляции 
эмоций в общении, ориентироваться на конституционно-правовые и этические нормы морали);

- поведенческий (государственная и личная ответственность за свои действия, готовность аргументированно отстаивать свои права, гражданскую позицию, преобразовывать гражданское общество и т.п.).

Для юридической деятельности будущему юристу важно приобрести гибкость в смене стиля коммуникации или отстаивания своей гражданской позиции при защите прав граждан и т.п. В современной педагогической науке деятельность определяется на основе субъектного значения, как условие воспроизводства человека, формирования у студентов позиции в учении, в практической деятельности, в поиске новых знаний и способов будущей профессиональной деятельности. Мы разделяем точку зрения А.А. Купавцева о том, что «...опыт деятельности проявляется в способности личности к преодолению встретившихся противоречий, в стремлении уйти от привычных стереотипов, увидеть и вычленить проблему» $[7$, с. 111]. В контексте деятельностного подхода, юридическая клиника представлена как субъектная деятельность студентов по приобретению опыта профессиональной деятельности в принятии ответственных решений в нестандартных ситуациях. Как пишет А.А. Исаев: «Знание необходимо «привязывать» к действию, к жизненным ситуациям, а в профессиональном образовании - к будущей профессиональной деятельности обучающегося) $[5$, с. 202].

Концептуальный компонент модели отражал следующие теоретические положения:

- гражданская позиция является личностно-профессиональной характеристикой, которая определяет активность человека в обществе, его систему мировоззрений и ответственность за принятые решения, что весьма значимо для будущей профессиональной деятельности юриста;

- социальная активность как проявление личностной и гражданской позиции человека, социальная активность будущего юриста проявляется в способности формулировать аргументированные доводы, суждения, умозаключения в неопределенных ситуациях.

- понимание значимости диалога обусловлено формированием социально-профессиональной компетентности студентов в разрешении проблем в непредвиденных конфликтных ситуациях, затрагивающих права и интересы личности в поликультурной многонациональной среде, в которой будет реализовываться профессиональная деятельность юриста.

- приоритет базовых ценностей в подготовке будущего юриста, которые отражают гражданскую идентичность, свободу личности, справедливость, служение Отечеству, закону, правовому обществу.

Целевой компонент. Целевой компонент направлен на создание педагогических условий формирования гражданской позиции будущих юристов в учебной и внеучебной деятельности согласно требованиям ФГОС ВО по направлению подготовки 40.03.01 Юриспруденция (бакалавриат). Основными задачами выступили:

Формирование компетенций в вопросах конституционных и правовых норм, этики и морали.

Развитие ценностных ориентаций, понимания государственной и личной ответственности за свои действия в становлении правового государства и правовой культуры граждан, воспитание уважительного отношения к своему государству и его гражданам.

Развитие способности к диалогу в рамках конституционно-правовых и этических норм морали, самоконтролю 
и саморегуляции эмоций в общении с гражданами.

Формирование опыта аргументированно отстаивать свои права и гражданскую позицию, преобразовывать гражданское общество соответственно конституционным и правовым нормам, этике и морали.

Содержательный компонент. Содержание образовательно-воспитательной деятельности в подготовке будущих юристов по направлению 40.03.01 Юриспруденция (бакалавриат) проектировалось на выше обозначенных принципах модульности, интеграции, межпредметных связях и представлено в теоретическом и прикладном аспектах. Теоретический аспект отражен в рабочей программе курса по выбору «Юридическая клиника - среда диалога и проявления гражданской позиции юриста) (36 час. 1 з.ед., зачет), включающего следующие модули.

Модуль 1 «Гражданская позиция будушего юриста» содержал основные понятия феномена «гражданственность», «гражданская позиция юриста»; значимость гражданской позиции юриста в его профессиональной деятельности; описание закономерных связей гражданской позиции и ответственности за принятые решения, гражданской позиции и личностных качеств; возможные риски в профессиональной деятельности юриста в ситуации общения с гражданами и выбора гражданской позиции в принятии правовых решений; способы саморазвития гражданской позиции юриста.

Модуль 2 «Диалог как профессиональный способ общения, просвещения, поддержки граждан в правовом поле» раскрывает понятие «диалога как профессионального инструментария юриста); специфику профессионального диалога юриста с гражданами различной категории и социальных слоев общества; особенности гражданской позиции юриста в различных непредвиденных/неопределенных ситуациях диалога с гражданами; социально-психологические средства саморегуляции эмоций юриста в конфликтных ситуациях общения с гражданами; принципы этики юриста в профессиональной деятельности и общении.

Модуль 3 «Юридическая клиника среда проявления гражданской позиции юриста» включает в себя понятие «юридическая клиника»; основные виды деятельности юриста в юридической клинике (консультативная, организационная, просветительская, профилактическая, правоохранительная, экспертно-консультационная и др.); содержание деятельности в юридической клинике (обоснование и принятие в пределах должностных обязанностей решений, совершение действий, связанных с реализацией правовых норм, составление юридических документов, обеспечение законности, правопорядка, безопасности личности, общества и государства и т.п.).

Технологический компонент. В процессе изучения курса по выбору «Юридическая клиника - среда диалога и проявления гражданской позиции юриста» будущие юристы осваивали следующие виды и функции диалога: диалог как способ получения информации от граждан; диалог как понимание намерений и ожиданий гражданина после юридической консультации; диалог как алгоритм действий юриста по оказанию качественной помощи гражданам в решении их правовых вопросов; диалог как личностная рефлексия гражданской позиции юриста; диалог как обмен информацией, оценками, успехами студента и наставника. Юридическая клиника рассматривалась как среда практической юридической деятельности, где будущие юристы осваивали самостоятельно или под руководством наставника (преподавателя, аспиранта, магистра) профессиональный опыт деятельности [1]: консультационная деятельности по вопросам права; просветительско-педагогическая деятельность будущего юриста; правоохранительная деятельность, 
«направленная на охрану и защиту прав граждан》 [8]; организационно-управленческая деятельность; правотворческая деятельность; правоохранительная деятельность, направленная на просвещение населения и подростков; экспертно-консультационная деятельность, связанная с юридической помощью по вопросам права. Оценочный компонент представлен ожидаемыми результатами, критериями гражданской позиции будущих юристов, оценочными средствами уровня сформированности гражданской позиции.

\section{Выводы}

Анализ исследований позволил выявить основные тренды развития юридического образования (интеграционные процессы, воспитание гражданина в процессе профессиональной подготовки, гуманизация, гуманитаризация и др.). В процессе юридического образования подготовка профессионала и воспитание гражданина диктуют поиск научно-теоретических подходов к проектированию новых моделей подготовки будущих юристов.

\section{ЛИТЕРАТУРА:}

1. Бурмакина М.И. Организация и управление юридической деятельностью. М., 2017. $48 \mathrm{c}$.

2. Васильев А.А., Куликов Е.А., Шпоппер Д. Высшее юридическое образование в России: некоторые современные тенденции, проблемы и перспективы развития // Российско-Азиатский правовой журнал Российское право: история и современность. 2019. № 1. С. 4-13.

3. Волкова Л.В., Волкова Ю.С. Личностные результаты: взгляд через призму средового подхода в воспитании // Гуманитарные исследования. Серия: Педагогика и психология. 2021. № 5. C. 9-17.

4. Еремина И.С. Развитие гражданственности как фактор профессионального становления будущего специалиста органов внутренних дел // Теория и практика общественного развития. 2011. № 2. С. 173-176.

5. Исаев А.А. Роль деятельностного подхода в современном образовательном процессе // Вестник Уфимского юридического института МВД России. 2021. № 1(91). С. 201-206.

6. Климов Е.А. Психология профессионального самоопределения: учебное пособие для студентов. М.: Академия, 2004. 304 с.

7. Купавцев А.А. Деятельностный подход к профессиональной подготовке в системе многоуровневого инженерного образования // Вестник МГТУ им. Н.Э. Баумана. Серия: Естественные науки. 2006. № 4. С. 106-119.

8. Лонь С. Л. Правоохранительная деятельность - основа для выделения правоохранительных органов // Российская правовая система: становление, проблемы, пути совершенствования: материалы республиканской научной конференции / под ред. В.К. Гавло, В.Я. Музюкина, В.В. Невинского. Барнаул: Алт. ун-т, 2001. С. 342-346.

9. Теоретические и методические аспекты подготовки студентов в области туризма / Поддубная Т.Н. [и др.] // Вестник Майкопского государственного технологического университета. 2017. Вып. 3. С. 61-66.

10. Иванова С.А., Пашенцев Д.А. Развитие высшего юридического образования: проблемы и перспективы // Право и образование. 2014. № 1. С. $42-47$.

11. Семенов Е.А. Профессиональное самосознание будущих юристов // Психопедагогика в правоохранительных органах. 2009. № 2(37). С. 19-22.

12. Сергеев В.В. Формирование демократической гражданственности в социально-профессиональной среде сотрудников органов внутренних дел: вопросы теории и практики // Защита и обеспечение прав человека в деятельности милиции: сборник учебных курсов. Пермь, 2010. 153 с. 
13. Сошникова Т:А. Некоторые проблемы обеспечения качества юридического образования в современной России // Образование и право. 2017. № 1. С. 67-73.

14. Сулима И.И. Среда и стихия в образовании: подходы к сущностной оценке // Стихии, стихийность и стихиальность в образовании: сборник научных статей / под ред. Ю.С. Мануйлова. М.; Н. Новгород, 2007. 145 с.

15. Томсинов В.А. Преступление под названием «юридический факультет» // Закон. 2009. № 3. C. 51-59.

16. Donetskaya O., Golovanova I. Constructivist Models of Teaching in Development of Civil Cosmpetencies and Personal Qualities of Students // Procedia - Social and Behavioral Science. 2015. Vol. 191, 2 June. P. 534-539.

17. Chalen Westaby, Andrew Fowler, Jake Phillips, Jaime Waters. Conformity, conflict and negotiation in criminal justice work: Understanding practice through the lens of emotional labour // International Journal of Law, Crime and Justice. 2020. Vol. 61, June. P. 100-390.

18. Jianan Guo, Muhammad Azizul Islam, Ameeta Jain, Chris J. van Staden. Civil liberties and social and environmental information transparency: A global investigation of financial institutions // The British Accounting Review Available online. 2021. 28 April. P. 101-118.

19. Raja Akermi, Abdelfattah Triki. The green energy transition and civil society in Tunisia: Actions, motivations and barriers // Energy Procedia: 4th International Conference on Energy and Environment Research, ICEER (17-20 July 2017). Porto, Portugal, 2017. P. $79-84$.

20. Sharon H., Mastraccilan T. Adams. It's not depersonalization, It's emotional labor // Examining surface acting and use-of-force with evidence from the US. 2020. Vol. 61. P. 100-358.

21. Tjahja N., Meyer T., Shahin J. What is civil society and who represents civil society at the IGF? An analysis of civil society typologies in internet governance // Telecommunications Policy. 2021. № 45. P. 102-141.

\section{REFERENCES:}

1. Burmakina M.I. Organization and management of legal activities. M., 2017. 48 p.

2. Vasiliev A.A., Kulikov E.A., Schopper D. Higher legal education in Russia: some modern trends, problems and development prospects // Russian-Asian legal journal Russian law: history and modernity. 2019. No. 1. P. 4-13.

3. Volkova L.V., Volkova.Yu.S. Personal results: a view through the prism of the environmental approach in education // Humanitarian research. Series: Pedagogy and Psychology. 2021. No. 5. P. 9-17.

4. Eremina I.S. Development of citizenship as a factor of professional formation of a future specialist of internal affairs bodies // Theory and practice of social development. 2011. No. 2. P. 173-176.

5. Isaev A.A. The role of the activity approach in the modern educational process // Bulletin of the Ufa Law Institute of the Ministry of Internal Affairs of Russia. 2021. No. 1 (91). P. 201-206.

6. Klimov E.A. Psychology of professional self-determination: a textbook for students. Moscow: Academy, 2004. 304 p.

7. Kupavtsev A.A. Activity approach to vocational training in the system of multilevel engineering education. Bulletin of MSTU named after N.E. Bauman. Series: Natural Sciences. 2006. No. 4. P. 106-119.

8. Lon S.L. Law enforcement activity - the basis for the selection of law enforcement bodies // The Russian legal system: formation, problems, ways of improvement: materials of the Republican scientific conference'/ ed. by V.C. Gavlo, V.Ya. Muzyukina, V.V. Nevinsky. Barnaul: Alt. un-t, 2001. P. 342-346. 
9. Theoretical and methodological aspects of training students in the field of tourism /. Poddubnaya T.N. [et al.] // Bulletin of Maykop State Technological University. 2017. Iss. 3. P. 61-66.

10. Ivanova S.A., Pashentsev D.A. Development of higher legal education: problems and prospects // Law and Education. 2014. No. 1. P. 42-47.

11. Semenov E.A. Professional self-awareness of future lawyers // Psychopedagogy in law enforcement agencies. 2009. No. 2 (37). P. 19-22.

12. Sergeev VIV: Formation of democratic citizenship in the social and professional environment of employees of internal affairs bodies: theory and practice // Protection and maintenance of human rights in the activities of the police: a collection of training courses. Perm, 2010. $153 \mathrm{p}$.

13. Soshnikova T.A. Some problems of ensuring the quality of legal education in modern Russia // Education and Law. 2017. No. 1. P. 67-73.

14. Sulima I.I. Environment and elements in education: approaches to essential assessment // Elements, spontaneity and spontaneity in education: collection of scientific articles / ed. Yu.S. Manuilova. M.; N. Novgorod, 2007. 145 p.

15. Tomsinov V.A. Crime called "Faculty of Law" // Law. 2009. No. 3. P. 51-59.

16. Donetskaya O., Golovanova I. Constructivist Models of Teaching in Development of Civil Cosmpetencies and Personal Qualities of Students // Procedia - Social and Behavioral Science. 2015. Vol. 191, 2 June. P. 534-539.

17. Chalen Westaby, Andrew Fowler, Jake Phillips, Jaime Waters. Conformity, conflict and negotiation in criminal justice work: Understanding practice through the lens of emotional labor // International Journal of Law, Crime and Justice. 2020. Vol. 61, June. P. 100-390.

18. Jianan Guo, Muhammad Azizul Islam Ameeta Jain, Chris J. van Staden. Civil liberties and social and environmental information transparency: A global investigation of financial institutions // The British Accounting Review Available online. 2021. 28 April. P. 101-118.

19. Raja Akermi, Abdelfattah Triki The green energy transition and civil society in Tunisia: Actions, motivations and barriers // Energy Procedia: 4th International Conference on Energy and Environment Research, ICEER (17-20 July 2017). Porto, Portugal, 2017. P. 79-84.

20. Sharon H., MastracciIan T. Adams. It's not depersonalization, It's emotional labor // Examining surface acting and use-offforce with evidence from the US. 2020. Vol. 61. P. 100-358.

21. Tjahja N., Meyer T., Shahin J. What is civil society and who represents civil society at the IGF? An analysis of civil society typologies in internet governance // Telecommunications Policy. 2021. No. 45. P. 102-141. 